\title{
Brain muscarinic receptors in progressive supranuclear palsy and Parkinson's disease: a positron emission tomographic study
}

\author{
Masato Asahina, Tetsuya Suhara, Hitoshi Shinotoh, Osamu Inoue, Kazutoshi Suzuki, \\ Takamichi Hattori
}

\begin{abstract}
Objectives-To assess muscarinic acetylcholine receptors ( $\mathrm{mAChRs)}$ in the brains of patients with progressive supranuclear palsy and Parkinson's disease, and to correlate the cholinergic system with cognitive function in progressive supranuclear palsy and Parkinson's disease.

Methods- Positron emission tomography (PET) and [ $\left.{ }^{11} \mathrm{C}\right] \mathrm{N}-m e t h y l-4-p i p e r i d y l$ benzilate $\left(\left[{ }^{11} \mathrm{C}\right] \mathrm{NMPB}\right)$ was used to measure $\mathrm{mAChRs}$ in the brain of seven patients with progressive supranuclear palsy, 12 patients with Parkinson's disease, and eight healthy controls. All of the patients with progressive supranuclear palsy were demented. The Parkinson's disease group consisted of 11 non-demented patients and one demented patient. The mini mental state examination (MMSE) was used to assess the severity of cognitive dysfunction in all of the subjects. The modified Wisconsin card sorting test (WCST) was used to evaluate frontal cognitive function in the non-demented patients with Parkinson's disease and controls.

Results-The mean $\mathrm{K}_{3}$ value, an index of mAChR binding, was significantly higher for the frontal cortex in the patients with Parkinson's disease than in the controls $(p<0.01)$. By contrast, the patients with progressive supranuclear palsy had no significant changes in the $K_{3}$ values of any cerebral cortical regions. The mean score of the MMSE in the progressive supranuclear palsy group was significantly lower than that in the control group. Although there was no difference between the Parkinson's disease and control groups in the MMSE, the non-demented patients with Parkinson's disease showed significant frontal lobe dysfunction in the WCST.

Conclusions-The increased $\mathrm{MAChR}$ binding in the frontal cortex of the patients with Parkinson's disease may reflect denervation hypersensitivity caused by loss of the ascending cholinergic input to that region from the basal forebrain and may be related to frontal lobe dysfunction in Parkinson's disease. The cerebral cortical cholinergic system may not have a major role in cognitive dysfunction in progressive supranuclear palsy.

(F Neurol Neurosurg Psychiatry 1998;65:155-163)
\end{abstract}

Keywords: progressive supranuclear palsy; Parkinson's disease; muscarinic receptor; positron emission tomography; cognitive dysfunction
Progressive supranuclear palsy is a neurodegenerative disorder characterised clinically by supranuclear gaze palsy, akinetic-rigid syndrome with dominant axial rigidity, frequent falls, and pseudobulbar palsy. ${ }^{12}$ In addition, cognitive dysfunction is one of the most common presenting symptoms in progressive supranuclear palsy. ${ }^{1-4}$ Albert et $a l^{\beta}$ coined the term "subcortical dementia" to describe this pattern of cognitive dysfunction. It has subsequently been applied to the cognitive dysfunction seen in other neurological disorders in which the primary pathology is thought to be in the subcortical structure, as in Parkinson's disease. ${ }^{4-6}$ The characteristic features are slowness of information processing, altered personality with apathy or depression, forgetfulness, and defective ability to manipulate acquired knowledge, ${ }^{36}$ all of which are similar to the characteristics of frontal lobe dysfunction. ${ }^{56}$

The pathophysiological basis of subcortical dementia, however, remains uncertain. Previously, we used PET and carbon-11 labelled $\mathrm{N}$-methyl-4-piperidyl benzilate $\left(\left[{ }^{11} \mathrm{C}\right] \mathrm{NMPB}\right)$ to measure muscarinic acetylcholine receptors (mAChRs) in the brain of eight patients with Parkinson's disease and found mAChR hypersensitivity in the frontal cortex, indicative of dysfunction of the ascending cholinergic system in that area. ${ }^{7}$ The cognitive dysfunction in Parkinson's disease may be related to impairment of the ascending cholinergic system which occurs in association with neuronal loss in the nucleus basalis of Meynert. ${ }^{7-11}$ In progressive supranuclear palsy, the cholinergic deficiency has been reported in some nuclei of the brainstem ${ }^{12-14}$ and basal forebrain, ${ }^{15}{ }^{16}$ and may be related to cognitive dysfunction as well as to oculomotor disturbance and akineticrigid syndrome. Here, we report the measurement of mAChRs in 12 patients with Parkinson's disease, including seven patients with Parkinson's disease from our previous report, ${ }^{11}$ and seven patients with progressive supranuclear palsy, and discuss the role of the ascending cholinergic system in these two diseases.

\section{Methods}

SUBJECTS

We studied 12 patients with Parkinson's disease ( 11 women and three men with a mean age of 59.1 years), seven patients with progressive supranuclear palsy (four women and three men with a mean age of 74.0 years), and eight control subjects (four women and four men with a mean age of 62.8) (table 1). 
Table 1 Patient profiles

\begin{tabular}{|c|c|c|c|c|c|c|c|c|c|}
\hline Case No & Age/ sex & $\begin{array}{l}\text { Duration of } \\
\text { illness }(y)\end{array}$ & Dementia ${ }^{\star}$ & $\begin{array}{l}\text { Supranuclear } \\
\text { down gaze palsy* }\end{array}$ & $\begin{array}{l}\text { Psuedobulbar } \\
\text { palsy }\end{array}$ & $\begin{array}{l}\text { Postural instability } \\
\text { and falls }\end{array}$ & $\begin{array}{l}\text { Greater axial than } \\
\text { limb rigidity }\end{array}$ & Tremor* & $\begin{array}{l}\text { Response to } \\
\text { levodopa }\end{array}$ \\
\hline \multicolumn{10}{|l|}{ PD: } \\
\hline 1 & $54 / \mathrm{F}$ & 1 & Nil & Nil & Nil & Nil & No & + & Good \\
\hline 2 & $68 / \mathrm{M}$ & 1 & Nil & Nil & Nil & Nil & No & + & Good \\
\hline 3 & $71 / \mathrm{F}$ & 1.5 & Nil & Nil & Nil & Nil & No & ++ & Good \\
\hline 4 & $60 / M$ & 3 & Nil & Nil & Nil & Nil & No & ++ & Good \\
\hline 5 & $60 / \mathrm{F}$ & 1 & Nil & Nil & Nil & $\mathrm{Nil}$ & No & ++ & Good \\
\hline 6 & $49 / \mathrm{M}$ & 3 & Nil & Nil & Nil & Nil & No & ++ & Good \\
\hline 7 & $62 / \mathrm{F}$ & 3 & Nil & Nil & Nil & + & No & ++ & Good \\
\hline 8 & $55 / \mathrm{F}$ & 5 & Nil & Nil & Nil & + & No & ++ & Good \\
\hline 9 & $35 / \mathrm{F}$ & 7 & Nil & Nil & Nil & + & No & +++ & Good \\
\hline 10 & $66 / \mathrm{F}$ & 6 & Nil & Nil & Nil & ++ & No & ++ & Good \\
\hline 11 & $60 / \mathrm{F}$ & 12 & Nil & Nil & Nil & ++ & No & ++ & Good \\
\hline 12 & $69 / \mathrm{F}$ & 6 & ++ & Nil & Nil & +++ & No & ++ & Good \\
\hline Mean & 59.2 & 4.1 & & & & & & & \\
\hline $\mathrm{SD}$ & 10.0 & 3.3 & & & & & & & \\
\hline \multicolumn{10}{|l|}{ PSP: } \\
\hline 13 & $70 / \mathrm{F}$ & 4 & ++ & +++ & Nil & ++ & Yes & Nil & Not tried \\
\hline 14 & $70 / \mathrm{F}$ & 3 & + & + & + & ++ & Yes & Nil & Poor \\
\hline 15 & $76 / \mathrm{F}$ & 4 & + & ++ & + & +++ & Yes & + & Poor \\
\hline 16 & $78 / \mathrm{M}$ & 6 & ++ & +++ & ++ & ++ & Yes & Nil & Poor \\
\hline 17 & $79 / \mathrm{M}$ & 6 & +++ & +++ & ++ & +++ & Yes & Nil & Poor \\
\hline 18 & $75 / \mathrm{F}$ & 7 & +++ & +++ & ++ & +++ & Yes & Nil & Poor \\
\hline 19 & $70 / \mathrm{M}$ & 13 & ++ & +++ & ++ & +++ & Yes & Nil & Poor \\
\hline Mean & 74.0 & 6.1 & & & & & & & \\
\hline $\mathrm{SD}$ & 4.0 & 3.3 & & & & & & & \\
\hline \multicolumn{10}{|c|}{ Control $(n=8)$ : } \\
\hline Mean & 62.8 & & & & & & & & \\
\hline SD & 10.8 & & & & & & & & \\
\hline
\end{tabular}

*Antiparkinsonian drug free.

$\mathrm{PSP}=$ progressive supranuclear palsy; $\mathrm{PD}=$ Parkinson's disease; $\mathrm{D}=$ levodopa; $\mathrm{DD}=$ levodopa + dopa decarboxylase; A=amitriptyline; TPH=trihexyphenidyl; $\mathrm{AH}=$ amantadine hydrochloride; $\mathrm{MMSE}=$ mini mental state examination; WCST $=\mathrm{W}$ isconsin card sorting test; CA=categories achieved; $\mathrm{TE}=$ total errors; $\mathrm{PEN}=$ perseverative errors of Nelson; DMS=difficulty in maintaining set.

All the patients with Parkinson's disease satisfied the research diagnostic criteria for Parkinson's disease ${ }^{17}$ and showed normal brain CT. One patient (12) had dementia on the basis of DSM-III-R criteria. ${ }^{18}$ The other 11 patients with Parkinson's disease were not demented; however, one (11) developed dementia a year after the PET study. Five patients with Parkinson's disease (1-3, 5, and 8), who responded well to levodopa after the PET study, had not taken any antiparkinsonian drugs before the PET study. The other patients with Parkinson's disease were treated with levodopa with dopa decarboxylase $(7,9$, and 12), dopa decarboxylase and amantadine hydrochloride (4, 6 and 10), or dopa decarboxylase and bromocriptine (11). None of the patients were treated with anticholinergic drugs before the PET study. The 12 patients with Parkinson's disease in this study included seven $(2,4-6,8,10$, and 11) from our previous report. ${ }^{11}$

All of the patients with progressive supranuclear palsy had supranuclear down gaze palsy, akinetic-rigid syndrome with dominant axial rigidity, postural instability, and dementia on the basis of the DSM-III-R criteria. ${ }^{18}$ Six had pseudobulbar palsy. Only one of the patients with progressive supranuclear palsy (15) showed tremor. All of them had no response or a poor response to levodopa, except for one patient (13), who was not tested with the drug. All of the patients with progressive supranuclear palsy underwent brain CT, which showed atrophy of the dorsal midbrain in six $(13,14$, and 16-19) and mild atrophy of the cerebral cortex in three (17-19). Four patients with progressive supranuclear palsy $(15,16,18$, and 19) had taken no neuropsychiatric drugs, including levodopa, before the PET study. The remaining patients with progressive supranuclear palsy had been treated with amitriptyline (13), dopa decarboxylase, trihexyphenidyl, and amantadine hydrochloride (14), and dopa decarboxylase (patient 17) before the PET study.

The eight control subjects were healthy volunteers, and none of them had a history of neurological or psychiatric disorders. None of the controls were treated with any drugs before the PET study.

Administration of all drugs in the patients with Parkinson's disease or progressive supranuclear palsy was discontinued at least four days before the PET study. Amytriptyline (patient 13) and trihexyphenidyl (patient 14) were discontinued two weeks before the PET study. Clinical status (mental status, neurological findings including parkinsonism, Hohen and Yahr stage, and neuropsychological tests; table 1) in the patients with Parkinson's disease or progressive supranuclear palsy was evaluated on the day before the PET studynamely, without antiparkinsonian drugs. The mini mental state examination (MMSE) ${ }^{19}$ was administered to assess the severity of cognitive impairment. The modified Wisconsin card sorting test (WCST) ${ }^{20}$ was used to assess frontal cognitive function in the 10 patients with Parkinson's disease $(1-8,10$, and 11) who were not demented and in all of the controls.

This study was approved by the ethics committee of the National Institute of Radiological Sciences, and informed written consent was obtained from all subjects.

\section{POSITRON EMISSION TOMOGRAPHY}

$\left[{ }^{11} \mathrm{C}\right] \mathrm{NMPB}$ was prepared by $\mathrm{N}$-methylation of 4-piperidyl benzilate with $\left[{ }^{11} \mathrm{C}\right]$ methyliodide. The radiochemical purity of the ligand was 
Table 1 Continued

\begin{tabular}{|c|c|c|c|c|c|c|}
\hline \multirow[b]{2}{*}{ Medication (mg/day) } & \multirow{2}{*}{$\begin{array}{l}\text { Hoehn and } \\
\text { Yahr stage }\end{array}$} & \multirow[b]{2}{*}{$M M S E^{\star}$} & \multicolumn{4}{|c|}{$W C S T^{\star}$} \\
\hline & & & $C A$ & $T E$ & PEN & $D M S$ \\
\hline Nil & 1 & 30 & 6 & 12 & 2 & 0 \\
\hline Nil & 1 & 30 & 3 & 31 & 6 & 1 \\
\hline Nil & 1 & 30 & 5 & 17 & 5 & 1 \\
\hline DD300,AH150 & 1 & 28 & 0 & 39 & 17 & 1 \\
\hline Nil & 2 & 30 & 5 & 16 & 6 & 0 \\
\hline DD300,AH150 & 2.5 & 30 & 6 & 12 & 1 & 0 \\
\hline DD300 & 3 & 30 & 4 & 12 & 1 & 2 \\
\hline Nil & 3 & 27 & 3 & 15 & 4 & 3 \\
\hline DD300 & 3 & 30 & & & & \\
\hline D600,AH150 & 4 & 25 & 3 & 30 & 17 & 0 \\
\hline DD200,B7.5 & 4 & 23 & 1 & 35 & 12 & 2 \\
\hline \multirow[t]{3}{*}{ DD300 } & 5 & 16 & & & & \\
\hline & 2.5 & 27.4 & 3.6 & 21.9 & 7.1 & 1.0 \\
\hline & 1.4 & 4.3 & 2.0 & 10.6 & 6.1 & 1.1 \\
\hline A 30 & 3 & 16 & & & & \\
\hline DD100,TPH4,AH200 & 4 & 19 & & & & \\
\hline Nil & 4 & 20 & & & & \\
\hline Nil & 4 & 15 & & & & \\
\hline DD100 & 5 & 2 & & & & \\
\hline Nil & 5 & 3 & & & & \\
\hline \multirow[t]{5}{*}{ Nil } & 5 & 12 & & & & \\
\hline & 4.3 & 12.0 & & & & \\
\hline & 0.8 & 7.4 & & & & \\
\hline & & 28.4 & 5.5 & 11.1 & 2.1 & 0 \\
\hline & & 1.9 & 0.7 & 4.5 & 3.8 & 0 \\
\hline
\end{tabular}

greater than $97 \%$, and the mean specific radioactivity 31.9 (range 4.6 to 52.8 ) GBq/idmol. A mean dose of 305 (range 190 to 400) $\mathrm{MBq}$ was infused intravenously to each subject. The brain radioactivity data were acquired on a four ring PET system (Hitachi Med Co, PCT3600W, 7 slice type) with an axial resolution of $12 \mathrm{~mm}$ and plane resolution of $8 \mathrm{~mm}$, full width at half maximum. The subjects' heads were positioned to obtain sections 8,22 , $36,50,64,78$, and $92 \mathrm{~mm}$ above and parallel to the orbitomeatal plane. A transmission scan for attenuation correction was made with a retractable ${ }^{68} \mathrm{Ge}-{ }^{68} \mathrm{Ga}$ source. Two minute serial scans were made for 60 minutes.

Regions of interest (ROIs) in the brain were delineated on integrated PET images obtained 0 to 60 minutes after injection. A rough outline of ROIs, including the surrounding CSF space and white matter, was delineated manually with reference to the brain atlas of Matsui and Hirano, ${ }^{21}$ and then the definitive ROIs were automatically defined within the boundaries of the just described outlines by a computer generated $70 \%$ isocontour for the cerebrum and a $55 \%$ isocontour for the cerebellum (fig 1 ). This method was chosen to reduce the partial volume effect. The ROIs of the frontal, temporal, and occipital cortex, and the striatum and thalamus were divided on the fourth plane. The parietal cortex and cerebellum were drawn on the seventh and second planes respectively. The average of right and left values was calculated for each brain region.

The kinetics of $\left[{ }^{11} \mathrm{C}\right] \mathrm{NMPB}$ in each brain region was analysed by the graphical method developed by Patlak et al. ${ }^{22}{ }^{23}$ In this study, cerebellar tissue activity was used as the input function, because the cerebellum has few specific mAChR binding sites. ${ }^{24}{ }^{25}$ In a preliminary study, we confirmed that pretreatment with intravenous injection of $30 \mathrm{mg} / \mathrm{kg}$ NMPB in a rhesus monkey did not significantly affect the $\left[{ }^{11} \mathrm{C}\right] \mathrm{NMPB}$ accumulation of radioactivity in the cerebellum despite inhibition of more than $80 \%$ in the cerebral cortex (unpublished data). We calculated the ratio of radioactivity in each target ROI to that in the cerebellum ( $A_{\text {target }} / A_{c b}$ ratio), and "the normalised time" by dividing the integrated cerebellar radioactivity by the actual cerebellar radioactivity at each time point. In each subject, the $A_{\text {target }} / A_{c b}$ ratio was plotted versus "the normalised time". As
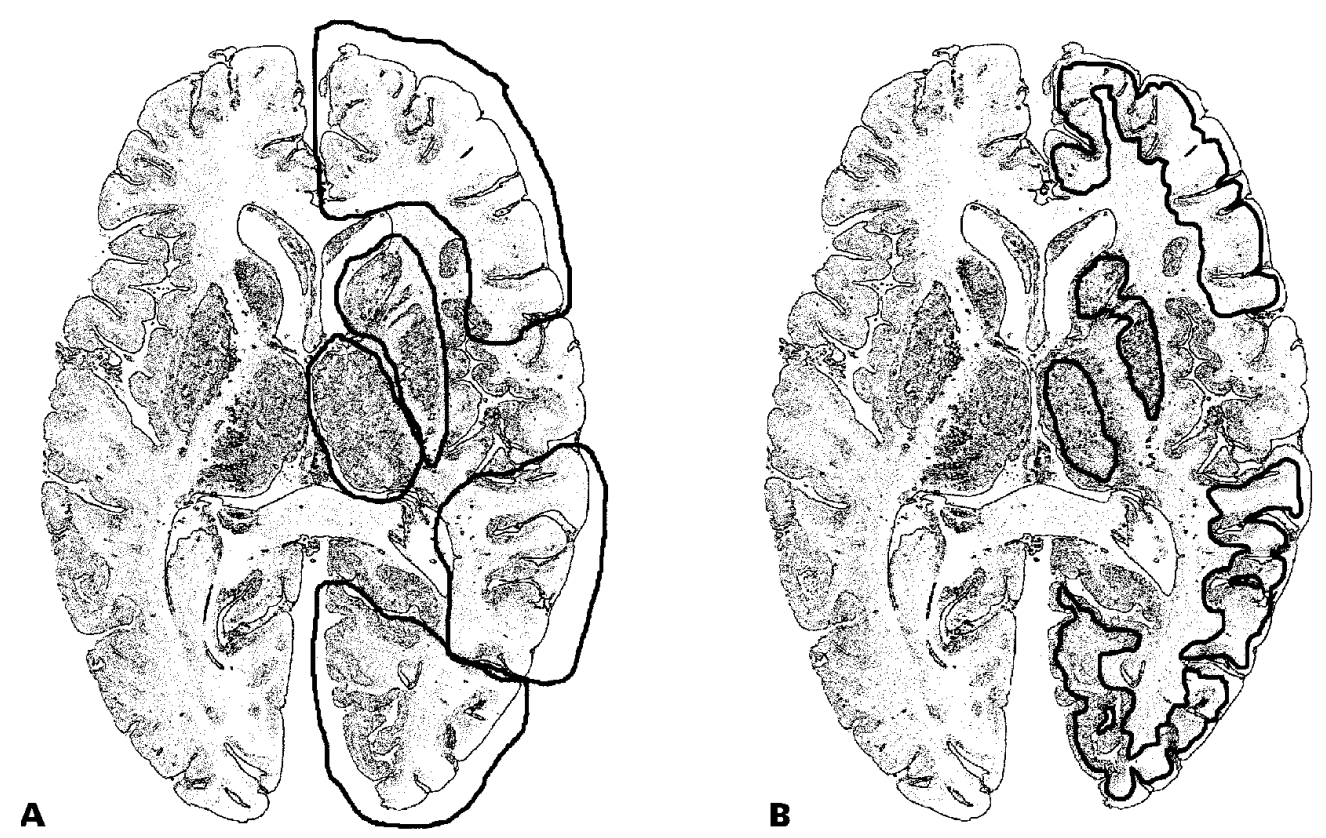

Figure 1 A process of ROI set up. (A) Outlines of ROIs were manually drawn first and then (B) ROIs were defined by computer controlled delineation of percentage isocontour. Illustrations were not PET images but modified cuts from the atlas of Matsui and Hirano. ${ }^{21}$ 


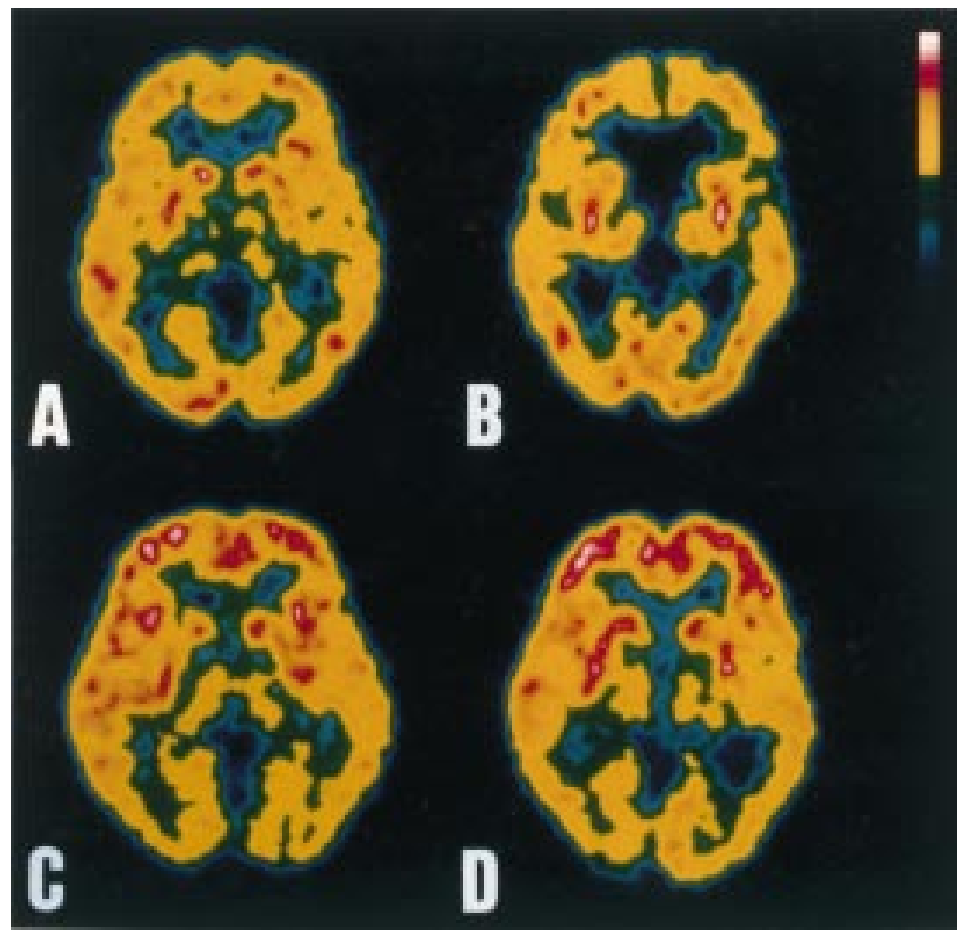

Figure 2 Integrated PET images of $\left[{ }^{11} C\right] N M P B$ uptake in $(A)$ a control subject, $(B)$ patient with progressive supranuclear palsy (13), (C) non-demented patient with Parkinson's disease (8), and (D) demented patient with Parkinson's disease (12) obtained 40 to 60 minutes after injection. There is a high accumulation of radioactivity in the frontal cortex of the patient with Parkinson's disease $(C, D)$, whereas the distribution of radioactivity is homogeneous in the patient with progressive supranuclear palsy (B) and the control $(A)$.

the $A_{\text {target }} / A_{c b}$ ratio increased linearly, the slope of the regression line $\left(\mathrm{K}_{3}\right)$ from 20 to $60 \mathrm{~min}$ utes was used to quantify $\mathrm{mAChR}$ binding. At tracer doses, $\mathrm{K}_{3}$ approximates to the product of the bimolecular association rate constant of receptor binding and the maximal binding capacity (Bmax). The ratios of the $\mathrm{K}_{3}$ values for the frontal, parietal, and temporal cortex to the value for the occipital cortex $(\mathrm{F} / \mathrm{O}, \mathrm{P} / \mathrm{O}$, and $\mathrm{T} / \mathrm{O}$ ratios) were calculated for each subject as the index of the relative distribution of $\mathrm{mAChR}$ binding in the cerebral cortex.

Metabolites of NMPB in the brain may affect $\mathrm{K}_{3}$ values in this analysis. However, the amount is thought to be negligible, because a metabolic study using a thin layer chromatographic method in our institute indicated that more than $95 \%$ of the radioactivity in the brain is unmetabolised $\left[{ }^{3} \mathrm{H}\right] \mathrm{NMPB}$ at 60 minutes after the injection in mice (unpublished data).

The $\mathrm{K}_{3}$ values and $\mathrm{F} / \mathrm{O}, \mathrm{P} / \mathrm{O}$, and $\mathrm{T} / \mathrm{O}$ ratios were normalised by logarithmic transformation. A one way analysis of variance (ANOVA)

Table 2 Pixels of ROI areas

\begin{tabular}{llll}
\hline Region & PSP & $P D$ & Control \\
\hline Frontal & $419.4(63.1)$ & $499.1(70.0)$ & $483.5(74.5)$ \\
Parietal & $473.0(75.9)$ & $556.9(78.4)$ & $580.1(47.4)$ \\
Temporal & $389.4(51.6)^{\star}$ & $601.8(86.7)$ & $603.8(90.4)$ \\
Occipital & $400.1(79.7)$ & $454.4(55.8)$ & $485.9(83.8)$ \\
Striatum & $215.0(61.5)$ & $254.8(40.1)$ & $256.0(30.0)$ \\
Thalamus & $120.7(16.8)$ & $152.2(29.1)$ & $161.0(29.1)$ \\
Cerebellum & $1123.4(156.0)$ & $1287.3(297.6)$ & $1312.6(283.8)$ \\
\hline
\end{tabular}

Values are mean (SD) of pixels. One pixel is $1.875 \times 1.875 \mathrm{~mm}^{2}$. RO=region of interest; $\mathrm{PSP}=$ progressive supranuclear palsy; $\mathrm{PD}=$ Parkinson's disease. ${ }^{\star} \mathrm{p}<0.005 v$ controls. was used to analyse the differences among the three groups in the $\mathrm{K}_{3}$ value of each ROI, age, and score of MMSE. Where group effects were found, post hoc comparisons were made using the Newman-Keuls test. Regional $\mathrm{K}_{3}$ differences among the three groups were first assessed using two way ANOVA. The student's $t$ test was used to test the significance of the differences between the 11 patients with Parkinson's disease and controls on the WCST. Multiple regressions were used to determine which factors (age, duration of illness, and scores on the MMSE and WCST) contributed to the differences in $\mathrm{K}_{3}$ values or $\mathrm{F} / \mathrm{O}$ ratio. Levels of significance were set at $\mathrm{p}<0.01$.

\section{Results}

There was a significant group effect for the mean score of the MMSE $(F=24.42$, $\mathrm{p}<0.000001$ ), and post hoc analysis showed that the mean score of the progressive supranuclear palsy group $(n=7)$ was significantly lower than the scores of the Parkinson's disease group $(\mathrm{n}=12, \mathrm{p}<0.0005)$ and control group $(n=8, p<0.0005)$. There was no difference between the Parkinson's disease $(n=12)$ and control groups in the MMSE. In the WCST, the Parkinson's disease group $(n=11)$ achieved fewer sorting categories $(\mathrm{p}<0.01)$, produced more total errors $(p<0.01)$ and perserverative errors of Nelson $(p<0.05)$, and had more difficulty in maintaining set $(\mathrm{p}<0.05)$ than the controls (table 1).

PET images (fig 2) showed that the uptake of $\left[{ }^{11} \mathrm{C}\right] \mathrm{NMPB}$ was highest in the striatum and cerebral cortex, moderate in the thalamus, and lowest in the cerebellum in all of the groups. The anatomical structure corresponding to each ROI was clearly distinguished on the PET images. The accumulation of $\left[{ }^{11} \mathrm{C}\right] \mathrm{NMPB}$ was uniformly distributed in the cerebral cortex of all the patients with progressive supranuclear palsy and controls. In six patients with Parkinson's disease $(2,3,5,6,11$, and 12$)$, the accumulation, however, was markedly increased in the frontal cortex compared with the other cerebral cortical areas.

Table 2 shows areas of ROIs, which were the sums of left and right regions. The mean ROI areas of the patients with progressive supranuclear palsy were not significantly different from those of the controls for all regions except the temporal cortex $(p<0.005)$. The mean ROI areas of the patients with Parkinson's disease were similar to those of controls for all regions.

In all of the subjects, radioactivity increased in each brain region except for the cerebellum during the 60 minutes after the $\left[{ }^{11} \mathrm{C}\right] \mathrm{NMPB}$ injection. In the cerebellum, the radioactivity peaked around 13 minutes and then decreased slowly until the end of the study (fig 3). ANOVAs were applied to analyse the differences in initial uptake of radioactivity in each ROI among the three groups. There were no significant differences in radioactivity of each ROI at any time points until 8 minutes. The $A_{\text {target }} / A_{c b}$ ratio plotted versus "the normalised time", gave straight lines that increased up to the end of measurement (fig 4). 

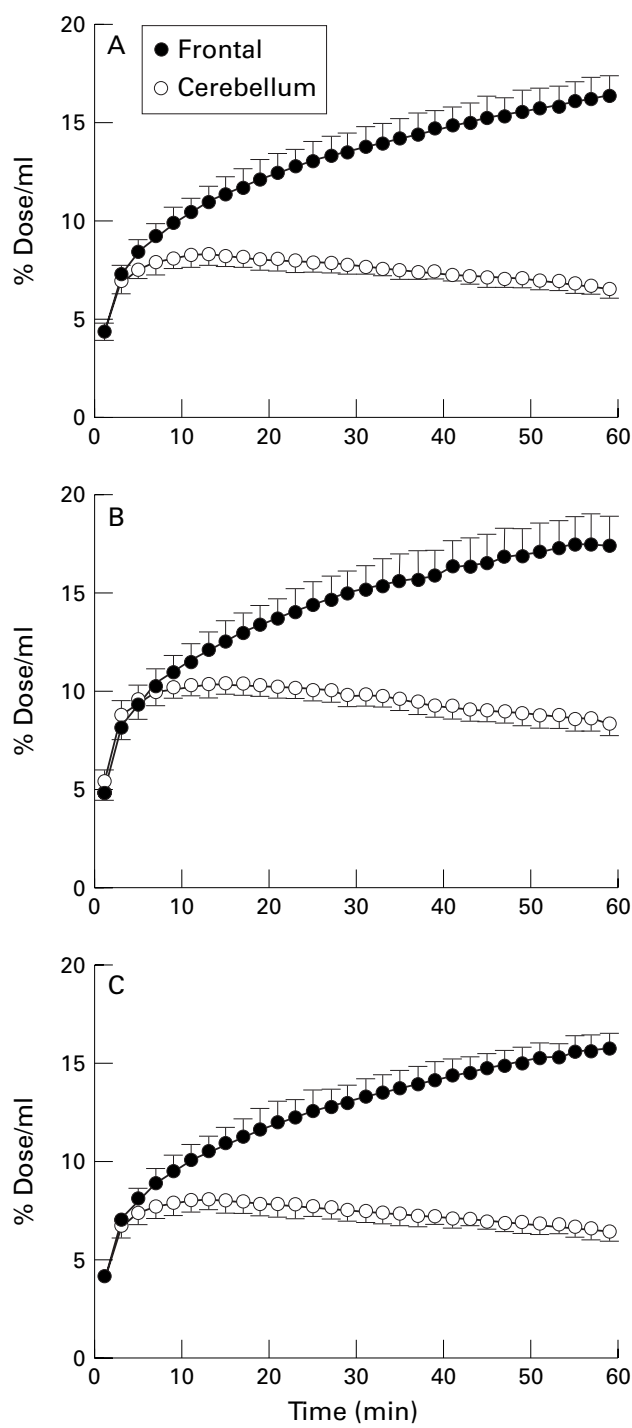

Figure 3 Time course of $\left[{ }^{11} C\right] N M P B$ accumulation in $(A)$ the Parkinson's disease group, $(B)$ the progressive supranuclear palsy group, and (C) controls. The means with SE bars are shown for the frontal cortex (solid circles) and cerebellum (open circles).

Table 3 shows the results of the $\mathrm{K}_{3}$ values. A two way ANOVA (factor 1 group; factor 2 region of ROI) showed a significant group effect $(F=11.36, \mathrm{p}=0.000026)$ and a significant region effect $\left(F=18.91, \mathrm{p}=0.2 \times 10^{-13}\right)$ for the $\mathrm{K}_{3}$ values of all ROIs. A group by region interaction was not significant $(F=1.27$, $\mathrm{p}=0.25)$. ANOVA showed a significant difference for group effect for the frontal cortex $(F=6.18, \mathrm{p}<0.01)$. In the post hoc test, the mean $\mathrm{K}_{3}$ value of the Parkinson's disease group was significantly higher $(22 \%)$ than that of the control group for the mean $\mathrm{K}_{3}$ value of the frontal cortex $(\mathrm{p}<0.01)$ (table 3, fig $5 \mathrm{~A}$ ). Patient 11, who showed dementia a year after the PET study, had the highest $\mathrm{K}_{3}$ value of the frontal cortex in all of the subjects. The $\mathrm{K}_{3}$ value in the patient with dementia (patient 12) was higher than the mean $+2 \mathrm{SD}$ of the $\mathrm{K}_{3}$ values in the controls for the frontal cortex. Although the mean $\mathrm{K}_{3}$ values of the Parkinson's disease group were higher than those of the controls for the parietal cortex $(+16 \%)$,

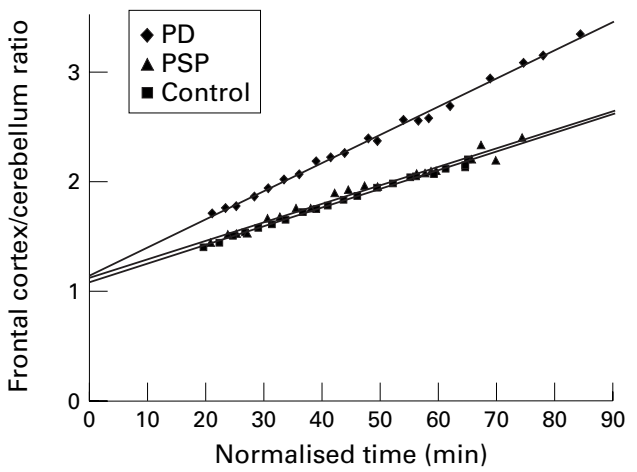

Figure 4 Plots for the patients with Parkinson's disease (patient 11) and those with progressive supranuclear palsy (patient 13) and a control showing the frontal/cerebellum ratios of $\left[{ }^{11} C\right] N M P B$ uptake against the expanded time scales of the integrated cerebellum/cerebellum counts. The plots are linear up to the end of PET measurement. The slopes are regarded as being $K_{3}$, which reflects $m A C h R$ binding potential in this study.

temporal cortex $(+16 \%)$, and striatum $(+16 \%)$, the differences were not significant. The mean $\mathrm{K}_{3}$ values of the patients with Parkinson's disease were not different from those of the controls for the occipital cortex and thalamus. In the progressive supranuclear palsy group, the $\mathrm{K}_{3}$ values were similar to those of controls for all cerebral regions.

The mean (SD) of the $\mathrm{F} / \mathrm{O}$ ratios was 1.22 (0.16) in the Parkinson's disease group, 0.97 (0.16) in the progressive supranuclear palsy group, and 0.98 (0.07) in the controls. There was a significant group effect for the $\mathrm{F} / \mathrm{O}$ ratio $(F=10.75, \mathrm{p}<0.0005)$, and post hoc analysis showed a highly significant difference between the Parkinson's disease group and the controls $(\mathrm{p}<0.005)$ (fig $5 \mathrm{~B})$. The mean $(\mathrm{SD})$ of the $\mathrm{T} / \mathrm{O}$ ratio was $1.12(0.14)$ in the Parkinson's disease group, 0.98 (0.08) in the progressive supranuclear palsy group and $0.96(0.09)$ in the controls. There was a significant group effect for the $\mathrm{T} / \mathrm{O}$ ratio $(F=6.32, \mathrm{p}<0.01)$, and post hoc analysis showed a significant difference between the Parkinson's disease group and the controls ( $p<0.01$, fig $5 \mathrm{C}$ ). The mean (SD) of the $\mathrm{P} / \mathrm{O}$ ratio was $1.21(0.19)$ in the Parkinson's disease group, $1.10(0.20)$ in the progressive supranuclear palsy group, and $1.03(0.13)$ in the controls. There were no significant differences in the $\mathrm{P} / \mathrm{O}$ ratios of the three groups (fig $5 \mathrm{D})$. The demented patient (patient 12) showed high $\mathrm{F} / \mathrm{O}, \mathrm{T} / \mathrm{O}$, and $\mathrm{P} / \mathrm{O}$ ratios, and the predemented patient (patient 11) showed high $\mathrm{F} / \mathrm{O}$ and $\mathrm{T} / \mathrm{O}$ ratios and a high $\mathrm{K}_{3}$ value in the frontal cortex (fig $5 \mathrm{~B}, \mathrm{C}, \mathrm{D}$ ). The $\mathrm{F} / \mathrm{O}, \mathrm{T} / \mathrm{O}$, and $\mathrm{P} / \mathrm{O}$ ratios in the progressive supranuclear palsy group did not yield significant differences from those in the controls.

In the Parkinson's disease and progressive supranuclear palsy groups, there was no significant correlation between the $\mathrm{K}_{3}$ value of each ROI and age, duration of disease, severity of disease, or scores on the MMSE. The patients with Parkinson's disease did not show a significant correlation between their $\mathrm{K}_{3}$ values or $\mathrm{F} / \mathrm{O}$ ratio, and scores on the WCST. 
Table 3 Distribution of regional $K_{3}$

\begin{tabular}{|c|c|c|c|c|c|c|}
\hline & Frontal & Parietal & Temporal & Occipital & Striatum & thalamus \\
\hline \multicolumn{7}{|c|}{ Parkinson's disease: } \\
\hline 1 & 0.0189 & 0.0193 & 0.0171 & 0.0176 & 0.0177 & 0.0128 \\
\hline 2 & 0.0242 & 0.0263 & 0.0220 & 0.0165 & 0.0265 & 0.0125 \\
\hline 3 & 0.0194 & 0.0204 & 0.0190 & 0.0143 & 0.0203 & 0.0103 \\
\hline 4 & 0.0187 & 0.0182 & 0.0171 & 0.0180 & 0.0195 & 0.0125 \\
\hline 5 & 0.0198 & 0.0196 & 0.0174 & 0.0148 & 0.0192 & 0.0120 \\
\hline 6 & 0.0238 & 0.0211 & 0.0222 & 0.0192 & 0.0239 & 0.0180 \\
\hline 7 & 0.0181 & 0.0196 & 0.0171 & 0.0161 & 0.0183 & 0.0122 \\
\hline 8 & 0.0187 & 0.0169 & 0.0175 & 0.0163 & 0.0180 & 0.0155 \\
\hline 9 & 0.0202 & 0.0204 & 0.0186 & 0.0174 & 0.0206 & 0.0140 \\
\hline 10 & 0.0199 & 0.0197 & 0.0191 & 0.0194 & 0.0229 & 0.0151 \\
\hline 11 & 0.0254 & 0.0242 & 0.0221 & 0.0199 & 0.0248 & 0.0153 \\
\hline 12 & 0.0218 & 0.0208 & 0.0197 & 0.0147 & 0.0225 & 0.0111 \\
\hline Mean & $0.0207^{\star}$ & 0.0206 & 0.0191 & 0.0170 & 0.0212 & 0.0134 \\
\hline SD & 0.0025 & 0.0025 & 0.0020 & 0.0019 & 0.0029 & 0.0022 \\
\hline \multicolumn{7}{|c|}{ Progressive supranuclear palsy: } \\
\hline 13 & 0.0203 & 0.0222 & 0.0191 & 0.0173 & 0.0171 & 0.0160 \\
\hline 14 & 0.0167 & 0.0172 & 0.0161 & 0.0173 & 0.0194 & 0.0118 \\
\hline 15 & 0.0203 & 0.0239 & 0.0190 & 0.0172 & 0.0173 & 0.0159 \\
\hline 16 & 0.0193 & 0.0152 & 0.0179 & 0.0200 & 0.0179 & 0.0083 \\
\hline 17 & 0.0112 & 0.0149 & 0.0135 & 0.0138 & 0.0158 & 0.0095 \\
\hline 18 & 0.0179 & 0.0217 & 0.0189 & 0.0191 & 0.0217 & 0.0184 \\
\hline 19 & 0.0125 & 0.0184 & 0.0153 & 0.0165 & 0.0126 & 0.0084 \\
\hline Mean & 0.0169 & 0.0191 & 0.0171 & 0.0173 & 0.0174 & 0.0126 \\
\hline SD & 0.0037 & 0.0036 & 0.0022 & 0.0020 & 0.0029 & 0.0041 \\
\hline \multicolumn{7}{|c|}{ Control $(n=8)$ : } \\
\hline Mean & 0.0170 & 0.0178 & 0.0165 & 0.0173 & 0.0183 & 0.0128 \\
\hline SD & 0.0024 & 0.0016 & 0.0023 & 0.0029 & 0.0032 & 0.0030 \\
\hline
\end{tabular}

${ }^{\star} \mathrm{p}<0.01 v$ controls.
$\mathrm{K}_{3}$ value. Nevertheless, such an explanation is unlikely for Parkinson's disease because CBF is reported to be unchanged ${ }^{3435}$ or decreased $^{36}$ in the frontal cortex of patients with Parkinson's disease. Brain CT of all the patients with Parkinson's disease showed no cerebral atrophy. In progressive supranuclear palsy, regional $\mathrm{CBF}$ is reported to be decreased in the cerebral cortex, striatum, and cerebellum, especially in the frontal cortex. ${ }^{34}{ }^{37}$ However, we calculated $\mathrm{K}_{3}$ values using brain radioactivity obtained after the peak on the cerebellar radioactivity curve (20 to 60 minutes after injection), when $\left[{ }^{11} \mathrm{C}\right] \mathrm{NMPB}$ uptake is near equilibrium across the blood-brain barrier, to minimise the possible effect of $\mathrm{CBF}$ on $\mathrm{K}_{3}$. In addition, there was no significant difference in the initial uptake of $\left[{ }^{11} \mathrm{C}\right] \mathrm{NMPB}$, which reflects regional $\mathrm{CBF}$, among the three groups (fig 3). Three patients with progressive supranuclear palsy (17-19) showed mild atrophy of the cerebral cortex on CT. Cerebral atrophy may lead to the underestimation of $\mathrm{K}_{3}$ values. The $\mathrm{K}_{3}$ value for the frontal cortex and $\mathrm{F} / \mathrm{O}$ ratio were low in two patients (17 and 19), who showed cerebral cortical atrophy on CT. In this study, ROIs were automatically defined by a computer generated isocontour to reduce the partial volume effect due to brain atrophy. However, It may be necessary to consider the possible effect of brain atrophy on $\mathrm{K}_{3}$ values in these patients.

The patients with progressive supranuclear palsy were significantly older than the patients with Parkinson's disease and controls. Binding of mAChR is reported to decrease with age, ${ }^{38} 39$ although the $\mathrm{K}_{3}$ values were not significantly correlated with age in any of the groups in this study. The age effect might have masked any increases of $\mathrm{K}_{3}$ values in the progressive supranuclear palsy group. We corrected the age effects on the $\mathrm{K}_{3}$ values of the patients with progressive supranuclear palsy, according to the report of Suhara et al (data not shown). ${ }^{39}$ However, we did not find any significant difference between the corrected mean $\mathrm{K} 3$ values in the progressive supranuclear palsy group and controls for any brain regions.

The present technique does not allow determination of whether the increased $\mathrm{K}_{3}$ was due to increased affinity or increased density of mAChR in Parkinson's disease in this study. Previous postmortem studies reported increased mAChR density, ${ }^{70}$ and increased ${ }^{7}$ and unchanged $^{10}$ mAChR affinity in the frontal cortex in Parkinson's disease. With the present technique, we could not determine whether the increased mean $\mathrm{K}_{3}$ value in the frontal cortex was due to increases of postsynaptic or presynaptic mAChRs, or both in Parkinson's disease in this study. Postsynaptic and presynaptic $\mathrm{mAChRs}$ are thought to be $\mathrm{M} 1$ and $\mathrm{M} 2$ receptors, respectively. ${ }^{40}$ The frontal cortex is especially rich in $\mathrm{M} 1$ receptors, and poor in M2 receptors. $^{24}{ }^{40}$ Lange et $a l^{10}$ reported that M1 receptors are increased, and M2 receptors are decreased in the frontal cortex of brains from patients with Parkinson's disease. Choline acetyltransferase (ChAT) activity is reported to be markedly reduced in the frontal cortex in Parkinson's disease. ${ }^{7810}$ Furthermore, 

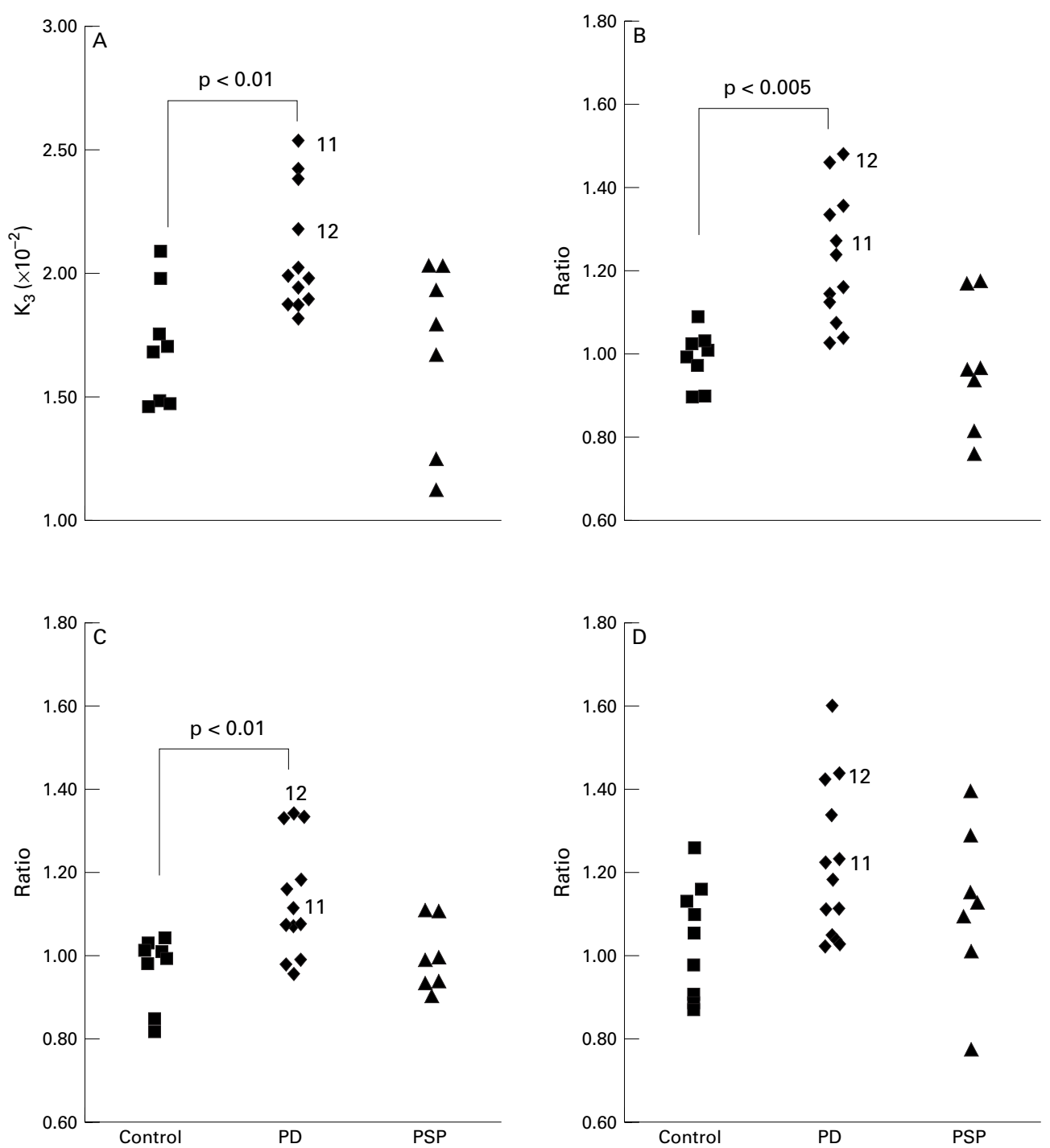

Figure 5 Scatter diagram showing data of individual patients for the three groups. $(A) K_{3}$ values in the frontal cortex. (B) The frontalloccipital cortex ratios of the $K_{3}$ values $\left(F / O\right.$ ratio). (C) The temporalloccipital cortex ratios of the $K_{3}$ values (T/O ratio). (D) The parietalloccipital cortex ratios of the $K_{3}$ values (P/O ratio). Numbers 11 and 12 beside symbols indicate patient 11 (predemented) and patient 12 (demented), respectively.

Parkinson's disease brains show a loss of the cholinergic neurons in the nucleus basalis of Meynert, ${ }^{16}{ }^{41}{ }^{42}$ which diffusely projects to the cerebral cortex, particularly the frontal and parietal cortex. ${ }^{43-46}$ These findings suggest the loss of presynaptic cholinergic neurons and increased postsynaptic $\mathrm{mAChR}$ in the frontal cortex in Parkinson's disease. Therefore, the increased $\mathrm{mAChR}$ binding in the frontal cortex of the patients with Parkinson's disease might reflect postsynaptic denervation hypersensitivity due to presynaptic cholinergic deficiency.

There is no report on changes in $\mathrm{mAChR}$ subtype in brain from patients with progressive supranuclear palsy. $M_{2}$ receptors may be decreased in the cerebral cortex, because neuronal loss in the nucleus basalis of Meynert is also seen in progressive supranuclear palsy. However, neuronal loss in progressive supranuclear palsy is mild compared with that in Parkinson's disease, ${ }^{16}$ and ChAT activity is unchanged $^{47}$ or mildly decreased ${ }^{32}$ in the cerebral cortex in progressive supranuclear palsy. These findings suggest that the deficit of presynaptic mAChR is mild in progressive supranuclear palsy. If this is the case, postsynaptic mAChR might not have remarkable denervation hypersensitivity.

In the striatum of patients with progressive supranuclear palsy, $\mathrm{mAChR}$ was reported to be unchanged in a study using $\left[{ }^{3} \mathrm{H}\right] \mathrm{QNB},{ }^{32}$ and reduced in a study using $\left[{ }^{3} \mathrm{H}\right] \mathrm{NMS} .^{33}$ The different results may be attributed to the different ligands used. Landwehrmeyer and Palacios ${ }^{33}$ speculated that reduction of $\left[{ }^{3} \mathrm{H}\right] \mathrm{NMS}$ binding sites in the striatum in progressive supranuclear palsy might reflect a loss of the M2 receptor thought to be expressed on cholinergic interneurons, which is decreased in the striatum in progressive supranuclear palsy. ${ }^{48}$ However, alteration of $\mathrm{M} 2$ receptors may not have a major effect on total $\mathrm{mAChR}$, because there are few M2 receptors, whereas there are numerous $M 1$ receptors in the striatum. ${ }^{24}{ }^{40} \mathrm{In}$ addition, ChAT activity has also been reported to be both unchanged ${ }^{47}$ and decreased ${ }^{32}$ in the striatum in progressive supranuclear palsy. 
Disruption of the cerebral cholinergic system has been postulated to have a major role in the cognitive dysfunction found in neurological diseases. Alzheimer's disease shows reduced cerebral cortical ChAT activity which is correlated with the degree of dementia. ${ }^{49}$ The decreased ChAT activity in the cerebral cortex in demented Parkinson's disease is as severe as that seen in Alzheimer's disease, and it is correlated with the degree of intellectual dysfunction. ${ }^{7-10}$ In this study, the WCST results indicated that even the non-demented patients with Parkinson's disease had frontal lobe dysfunction. Cognitive dysfunction in the patients with Parkinson's disease may be attributed to cholinergic deficits in the frontal cortex as suggested by the hypersensitivity of the mAChRs. The patient (12) who had dementia showed a high $\mathrm{K}_{3}$ value in the frontal cortex and high $\mathrm{F} / \mathrm{O}, \mathrm{T} / \mathrm{O}$, and $\mathrm{P} / \mathrm{O}$ ratios. In addition, the patient (11) who developed dementia a year later, showed the highest K3 value in the frontal cortex, and high $\mathrm{F} / \mathrm{O}$, and $\mathrm{T} / \mathrm{O}$ ratios (fig 5). However, we did not find a significant correlation between the WCST results and $\mathrm{K}_{3}$ values for the frontal cortex in Parkinson's disease. As the increased $\mathrm{K}_{3}$ values just reflect postsynaptic compensative changes, the increase in $\mathrm{K}_{3}$ values may not be simply proportional to the degree of presynaptic cholinergic deficiency.

Our patients with progressive supranuclear palsy did not show an alteration of $\mathrm{MAChR}$ in the cerebral cortex, although all of them had dementia. Kish et $a l^{47}$ suggested that the cognitive impairment in progressive supranuclear palsy is probably related to changes in the noncholinergic neurotransmitter system, because they found no reduction of ChAT activity in the cerebral cortex, hippocampus, and amygdala in demented patients with progressive supranuclear palsy. By contrast, Ruberg et $a l^{32}$ reported that the innominatocortical cholinergic system may have a role in intellectual dysfunction in progressive supranuclear palsy, because they found decreased ChAT activity in the frontal cortex. However, the reduction of ChAT activity in progressive supranuclear palsy $(-21 \%)$ was mild compared with that in Parkinson's disease $(-40 \%)$ in their study. ${ }^{72}$ In addition, neuronal loss in the nucleus basalis of Meynert in progressive supranuclear palsy is more mild than that in Parkinson's disease. ${ }^{16}$ Javoy-Agid $^{50}$ recently argued that progressive supranuclear palsy is not associated with a marked cholinergic deficiency in the cerebral cortex. Taken together, these findings suggest that the innominatocortical cholinergic system may not have a major role in cognitive disturbance in progressive supranuclear palsy.

1 Steele JC, Richardson JC, Olszewski J. Progressive supranuclear palsy. Arch Neurol 1964;10:333-59.

2 Collins SJ, Ahlskog JE, Parisi JE, et al. Progressive supranuclear palsy: neuropathologically based diagnostic clinical criteria. F Neurol Neurosurg Psychiatry 1995;58:167-73.

3 Albert ML, Feldman RG, Willis AL. The subcortical dementia of progressive supranuclear palsy. $\mathcal{F}$ Neurol dementia of progressive supranucl
Neurosurg Psychiatry 1974;37:121-30.

4 Brown RG, Marsden CD. Subcortical dementia: the neuropsychological evidence. Neuroscience 1988;25:36387.

5 Taylor AE, Saint-Cyr JA, Lang AE. Frontal lobe dysfunction in Parkinson's disease. Brain 1986;109:845-83.
6 Pillon B, Dubois B, Agid Y. Testing cognition may contribute to the diagnosis of movement disorders. Neurology 1996;46:329-34.

7 Ruberg M, Ploska A, Javoy-Agid F, et al. Muscarinic binding and choline acetyltransferase activity in parkinsonian subjects with reference to dementia. Brain Res 1982;232: 129-39.

8 Dubois B, Ruberg M, Jacovy-Agid F, et al. A subcorticocortical cholinergic system is affected in Parkinson's disease. Brain Res 1983;288:213-18.

9 Perry EK, Curtis M, Dick DJ, et al. Cholinergic correlates of cognitive impairment in Parkinson's disease: comparisons with Alzheimer's disease. $\mathcal{F}$ Neurol Neurosurg Psychiatry with Alzheimer's

10 Lange KW, Wells FR, Jenner P, et al. Altered muscarinic and nicotinic receptor densities in cortical and subcortical brain egions in Parkinson's disease. $\mathcal{F}$ Neurochem 1993;60:197203.

11 Asahina M, Shinotoh H, Hirayama K, et al. Hypersensitivity of cortical muscarinic receptors in Parkinson's disease demonstrated by PET. Acta Neurol Scand 1995;91:437-43.

12 Zweig RM, Whitehouse PJ, Casanova MF, et al. Loss of pedunculopontine neurons in progressive supranuclear palsy. Ann Neurol 1987;22:18-25.

13 Juncos JL, Hirsch EC, Malessa S, et al. Mesencephalic cholinergic nuclei in progressive supranuclear palsy. Neurology 1991;41:25-30.

14 Malessa S, Hirsch EC, Cervera P, et al. Progressive supranuclear palsy: loss of choline-acetyltransferase-like immunoreactive neurons in the pontine reticular formation. Neurology 1991;41:1593-7.

15 Tagliavini F, Pilleri G, Gemignani F, et al. Neuronal loss in the basal nucleus of Meynert in progressive supranuclear palsy. Acta Neuropathol (Berl) 1983;61:157-60.

16 Rogers JD, Brogan D, Mirra SS. The nucleus basalis of Meynert in neurological disease: a quantitative morphological study. Ann Neurol 1985;17:163-70.

17 Ward CD, Gibb WR. Research diagnostic criteria for Parkinson's disease. In: Streifler MB, Korczyn AD, Melamed E, et al, eds. Advances in neurology. Vol 53. Parkinson's disease: anatomy, pathology, and therapy. New York: Ron's disease: anatomy, pathol

18 American Psychiatric Association. Diagnostic and statistical manual of mental disorders, 3rd ed, revised. Washington, DC: APA, 1987

19 Folstein MF, Folstein SE, McHugh PR. Mini-mental state. A practical method for grading the cognitive state of patients for the clinician. F Psychiatr Res 1975;12:189-98.

20 Kashima H, Handa T, Kato M, et al. Neuropsychological investigation on chronic schizophrenia-aspects of its frontal functions. In: Takahashi R, Flor-Henry P, Gruzelier J, et al, eds. Cerebral dynamics, laterality and psychopathology. Amsterdam: Elsevier, 1987:337-45.

21 Matsui T, Hirano A. An atlas of the human brain for computerized tomography. Tokyo: Igaku Shoin, 1976.

22 Patlak CS, Blasberg RG, Fenstermacher JD. Graphical evaluation of blood-to-brain transfer constants from multiple-time uptake data. f Cereb Blood Flow Metab 1983; 3:1-7.

23 Patlak CS, Blasberg RG. Graphical evaluation of blood-tobrain transfer constants from multiple-time uptake data. Generalizations. F Cereb Blood Flow Metab 1985;5:584-90.

24 Lin S-C, Olson KC, Okazaki H, et al. Studies on muscarinic binding sites in human brain identified with $\left[{ }^{3} \mathrm{H}\right]$ pirenzepine. F Neurochem 1986;46:274-9.

25 Mulholland GK, Kilbourn MR, Sherman P, et al. Synthesis, in vivo biodistribution and dosimetry of $\left[{ }^{11} \mathrm{C}\right] \mathrm{N}-$ in vivo biodistribution and dosimetry of $\left[{ }^{11} \mathrm{C}\right] \mathrm{N}-$ tylcholine receptor antagonist. Nucl Med Biol 1995;22:1317.

26 Biel JH, Abood LG, Hoya WK, et al. Central stimulants. II. cholinergic blocking agents. Fournal of Organic Chemistry 1961;26:4096-103.

27 Rehavi M, Yaavetz B, Kloog Y, et al. In vivo and in vitro studies on the antimuscarinic activity of some amino esters of benzilic acid. Biochem Pharmacol 1978;27:1117-24.

28 Otto CA, Mulholland GK, Perry SE, et al. In vitro and ex vivo evaluation of cyclic aminoalkyl benzilates as potential emission tomor Nucl Med Biol 1989;16:51-5.

29 Tejani-Butt SM, Luthin GR, Wolfe BB, et al. N-substituted derivatives of 4-piperidinyl benzilate: affinities for brain

30 Koeppe RA, Frey KA, Zubieta JA, et al. Tracer kinetic analysis of [C-11]N-methyl-4-piperidyl benzilate binding to muscarinic cholinergic receptors. $\mathcal{f}$ Nucl Med 1992;33: to $\mathrm{m}$.

31 Kloog Y, Egozi Y, Sokolovsky M. Characterization of muscarinic acetylcholine receptors from mouse brain: evidence for regional heterogeneity and isomerization. $\mathrm{Mol}$ Pharmacol 1979;15:545-58.

32 Ruberg M, Javoy-Agid F, Hirsch E, et al. Dopaminergic and cholinergic lesions in progressive supranuclear palsy. Ann Neurol 1985;18:523-9.

33 Landwehrmeyer B, Palacios JM. Alterations of neurotransmitter receptors and neurotransmitter transporters in progressive supranuclear palsy. F Neural Transm Suppl 1994;42: 229-46.

34 Brooks DJ, Ibanez V, Sawle GV, et al. Striatal $\mathrm{D}_{2}$ receptor status in patients with Parkinson's disease, striatonigral degeneration, and progressive supranuclear palsy, measured with ${ }^{11} \mathrm{C}$-raclopride and positron emission tomography. Ann Neurol 1992;31:184-92. 
35 Wolfson LI, Leenders KL, Brown LL, et al. Alterations of regional cerebral blood flow and oxygen metabolism in regional cerebral blood flow and oxygen metab
Parkinson's disease. Neurology 1985;35:1399-405.

36 Jagust WJ, Reed BR, Martin EM, et al. Cognitive function and regional cerebral blood flow in Parkinson's disease. Brain 1992;115:521-37.

37 Leenders KL, Frackowiak RSJ, Lees AJ. Steele-RichardsonOlszewski syndrome. Brain energy metabolism, blood flow and fluorodopa uptake measured by positron emission tomography. Brain 1988;111:615-30.

38 Dewey SL, Volkow ND, Logan J, et al. Age-related decreases in muscarinic cholinergic receptor binding in the human brain measured with positron emission tomography (PET) f Neurosci Res 1990;27:569-75.

39 Suhara T, Inoue O, Kobayashi K, et al. Age-related changes in human muscarinic acetylcholine receptors measured by positron emission tomography. Neurosci Lett 1993;149. positron.

40 Flynn DD, Mash DC. Distinct kinetic binding properties of $\mathrm{N}-\left[{ }^{3} \mathrm{H}\right]-$ methylscopolamine afford differential labeling and $\mathrm{N}-\left[{ }^{3} \mathrm{H}\right]$-methylscopolamine afford differential labeling and
localization of $\mathrm{M} 1, \mathrm{M} 2$, and $\mathrm{M} 3$ muscarinic receptor sublocalization of M1, M2, and M3 muscarinic recept
types in primate brain. Synapse 1993;14:283-96.

41 Whitehouse PJ, Hedreen JC, White CL 3rd, et al. Basal Whitehouse PJ, Hedreen JC, White CL 3rd, et al. Basa
forebrain neurons in the dementia of Parkinson's disease. forebrain neurons in the dem
Ann Neurol 1983;13:243-8.

42 Nakano I, Hirano A. Parkinson's disease: neuron loss in the nucleus basalis without concomitant Alzheimer's disease. Ann Neurol 1984;15:415-8.
43 Kievit J, Kuypers HGJM. Basal forebrain and hypothalamic connections to frontal and parietal cortex in the Rhesus monkey. Science 1975;187:660-2.

44 Divac I. Magnocellular nuclei of the basal forebrain project to neocortex, brain stem, and olfactory bulb. Review of some functional correlates. Brain Res 1975;93:385-98.

45 Mesulam MM, Van Hoesen GW. Acetylcholinesterase-rich projections from the basal forebrain of the rhesus monkey to neocortex. Brain Res 1976;109:152-7.

46 Jones EG, Burton H, Saper CB, et al. Midbrain, diencephalic, and cortical relationships of the basal nucleus of Meynert and associated structures in primates. F Comp Neurol 1976;167:385-419.

47 Kish SJ, Chang LJ, Mirchandani L, et al. Progressive supranuclear palsy: relationship between extrapyramidal disturbances, dementia, and brain neurotransmitter markers. Ann Neurol 1985;18:530-6.

48 Oyanagi K, Takahashi K, Wakabayashi K, et al. Selective decrease of large neurons in the neostriatum in progressive supranuclear palsy. Brain Res 1988;458:218-23

49 Wilcock GK, Esiri MM, Bowen DM, et al. Alzheimer's disease. Correlation of cortical choline acetyltransferase activity with the severity of dementia and histological abnormalities. $\mathcal{F}$ Neurol Sci 1982;57:407-17.

50 Javoy-Agid F. Cholinergic and peptidergic systems in PSP. $\mathcal{F}$ Neural Transm Suppl 1994;42:205-18.

\section{Fournal of Neurology Neurosurgery and Psychiatry - http://www.jnnp.com}

Visitors to the world wide web can now access the fournal of Neurology Neurosurgery and Psychiatry either through the BMJ Publishing Group's home page (http://www.bmjpg.com) or directly by using its individual URL (http://www.jnnp.com). There they will find the following:

- Current contents list for the journal

- Contents lists of previous issues

- Members of the editorial board

- Subscribers' information

- Instructions for authors

- Details of reprint services.

A hotlink gives access to:

- BMJ Publishing Group home page

- British Medical Association web site

- Online books catalogue

- BMJ Publishing Group books.

The web site is at a preliminary stage and there are plans to develop it into a more sophisticated site. Suggestions from visitors about features they would like to see are welcomed. They can be left via the opening page of the BMJ Publishing Group site or, alternatively, via the journal page, through "about this site". 